\title{
Intersexual copying by sneaker males of the peacock blenny
}

\author{
DAVID GONÇALVES*, RUI F. OLIVEIRA*, KAY KÖRNER† \& INGO SCHLUPP† \\ *Unidade de Investigação em Eco-Etologia, ISPA \\ $\nmid$ Zoologisches Institut und Zoologisches Museum, Universität Hamburg, Germany \\ (Received 12 March 2002; initial acceptance 9 April 2002; \\ final acceptance 27 July 2002; MS. number: 7256R)
}

\begin{abstract}
In general, animals prefer to mate with individuals they have observed being courted or in close association with sexual partners. This phenomenon of mate copying has been demonstrated in several species, but so far no study has provided substantial evidence that it is adaptive. Furthermore, mate copying has been viewed only in the context of females copying other females or males copying other males. In the peacock blenny, Salaria pavo, parasitic males (sneakers) may gain an advantage by copying the association patterns of females with bourgeois males (large males that defend nests). We tested the sneaker's preference for one of two males and subsequently presented the nonpreferred male to the sneaker in the company of females, while the preferred male was presented alone. If the association of females with bourgeois males influences the sneaker's preference, we predicted the sneaker would spend more time close to the nonpreferred male, when females were no longer present. We found that (1) sneakers preferred to associate with the larger of the two males and (2) when the previously nonpreferred male was presented in the company of females the sneakers tended to approach that male sooner, although not significantly so, and to spend more time close to it. Thus, parasitic males seem to choose host males both by independent mechanisms (larger males were preferred) and by nonindependent mechanisms (males observed with females were preferred). We discuss the adaptive value of sneakers choosing males by each of these mechanisms.
\end{abstract}

() 2003 The Association for the Study of Animal Behaviour. Published by Elsevier Science Ltd. All rights reserved.

Mate copying is an example of a nonindependent mechanism in which individual mate choice is influenced by the direct observation of the choices of others (e.g. Losey et al. 1986; Dugatkin 1992; Pruett-Jones 1992; Kraak 1996; Westneat et al. 2000). In general, animals prefer to mate with sexual partners that have been observed mating, being courted or in close association with members of the opposite sex. Female mate copying is found in mating systems that are not resource based and has been suggested for several species (e.g. fish: Poecilia reticulata: Dugatkin 1992; Oryzias latipes: Grant \& Green 1996; Poecilia latipinna: Witte \& Ryan 1998, 2002; birds: Coturnix coturnix japonica: Galef \& White 1998; Tetrao tetrix: Höglund et al. 1995). Heterospecific female copying and male mate copying have also been demonstrated in one fish species (P. latipinna: Schlupp et al. 1994; Schlupp \& Ryan 1997).

It is unclear, however, how general mate copying is as a phenomenon, as a number of studies have failed to document its existence (e.g. fish: P. reticulata: Brooks

Correspondence: D. Gonçalves, Eco-Ethology Research Unit, ISPA, Rua Jardim do Tabaco 34, 1049-041 Lisboa, Portugal (email: davidg@ispa.pt. I. Schlupp is now at the Zoologisches Institut, Universität Zürich, Winterthurerstrasse 190, CH-8057 Zürich, Switzerland.
1999; birds: Ficedula hypoleuca: Slagsvold \& Viljugrein 1999; Gallinago media: Fiske at al. 1996). Furthermore, in two fish species for which mate copying was reported, subsequent studies were unable to confirm these findings (P. reticulata: Lafleur et al. 1997; but see Dugatkin 1998; O. latipes: Howard et al. 1998). More importantly, the evolutionary significance of mate copying is still unclear, although several potential advantages have been suggested. For example, Dugatkin \& Godin (1993) proposed that younger females may copy the choices of older females to avoid errors and Schlupp \& Ryan (1997) suggested that males copy the choices of other males to favour the detection of receptive females. Recent theoretical models suggest that mate copying could spread through indirect selection (Servedio \& Kirkpatrick 1996) and be important for the evolution of male ornaments (Agrawal 2001).

Mate choice copying has so far been viewed only in the context of females copying other females or males copying other males (reviewed in Westneat et al. 2000). Here we broadened this perspective by studying whether the choices of host males by parasitic males of the peacock blenny, Salaria pavo, are based solely on independent mechanisms or are influenced by the choices of conspecific females. 
Salaria pavo is a small intertidal fish occurring along temperate Mediterranean and Atlantic rocky coasts (Zander 1986). It has a strong sexual dimorphism: males are larger than females and have a well-developed head crest and an anal gland in the first two rays on the anal fin (Fishelson 1963; Papaconstantinou 1979; Patzner et al. 1986; Patzner \& Seiwald 1987). The mating system is usually promiscuous where the same male may spawn with several females throughout the breeding season and a female may lay her eggs with more than one male (Patzner et al. 1986). During the breeding season males defend nests in crevices or holes and take care of eggs (Patzner et al. 1986).

In southern Portugal, however, one population of S. pavo has a substantially different mating system. Here the fish inhabit an extensive intertidal mudflat area that has a shortage of hard substrate appropriate for nesting. The only hard substrates available are bricks and tiles used by clam culturists to delimit the frontiers of their fields and males use these materials for nesting. This leads to strong competition between males for nests. Males avoid leaving the nest and do not defend territories (Almada et al. 1994). At the peak of the breeding season most nests are fully covered with eggs and become a limiting factor for female spawning (Almada et al. 1994). The situation promotes two peculiarities of this mating system.

(1) The sex roles are reversed with females having the most active role in courtship (Almada et al. 1995). Females approach nesting males with a typical nuptial coloration, beating the pectoral fins rapidly and opening and closing the mouth in synchrony, while males are usually passive (Almada et al. 1995).

(2) Small males cannot compete for nests and adopt alternative reproductive tactics, acting as sneakers. They approach nest-holder males (bourgeois males, sensu Taborsky 1997) mimicking the females' morphology and behaviour and trying to fertilize the eggs parasitically (Gonçalves et al. 1996). Sneakers are fully mature and their gonadosomatic index is typically higher than that of bourgeois males (Gonçalves et al. 1996). Sneakers could adopt at least two tactics to optimize their access to spawning events. (a) They could follow females that are ready to spawn and try to intercept matings but this strategy may be conspicuous and costly. (b) They could choose bourgeois males that are likely to receive matings. As long as the preferences of females and sneakers match, this should be an efficient tactic. Focal observations on the behaviour of $S$. pavo sneakers in the field suggest that sneakers do associate with bourgeois males that are also preferred by females (D. Gonçalves, unpublished data).

This system thus provides ideal conditions for copying to occur. Spawning itself is not easily observed by other fish because females lay their eggs inside dark crevices or holes. However, female courting is conspicuous and probably reflects female mate choice. Both other females and sneakers could use this information to choose the males with whom to lay or parasitize eggs, respectively.

Sneakers may benefit from associating with males previously seen being courted by females, so that they can be present during future spawning events and fertilize the eggs parasitically. On the other hand, the choices of males may rely on independent mechanisms, as in nature larger bourgeois males receive more eggs (Oliveira et al. 1999; Gonçalves et al. 2002). Associating with larger males should increase the probability of a sneaker participating in spawning events.

We investigated whether sneakers base their preferences on the body size of bourgeois males and, if so, whether it is possible to manipulate this preference by staging an encounter with females. First, we presented a pair of bourgeois males to a sneaker and tested whether the sneaker showed a consistent preference for one of the males. We then presented the nonpreferred male in the company of females to the sneaker while the previously preferred male was presented alone. Subsequently, the females were removed and we tested the sneaker's preference for the males again. We predicted that if sneakers rely exclusively on independent mechanisms to choose host males their preference should not change from the first to the second part of the experiment. On the other hand, if sneakers use information from social interactions between males and females to choose their hosts, the sneaker should modify its preference.

\section{METHODS}

\section{Study Animals}

All fish were collected with a hand net at low tide at the Ria Formosa Nature Park (Algarve, Portugal; $36^{\circ} 59^{\prime} \mathrm{N}$, $\left.7^{\circ} 51^{\prime} \mathrm{W}\right)$ throughout the species' breeding season. Before the experiments, females, bourgeois males and sneakers were kept in three separate stock tanks $(60 \times 30 \mathrm{~cm}$ and $35 \mathrm{~cm}$ high) provided with abundant shelter. We combined two criteria to identify sneakers: (1) their morphology had to resemble females, lacking all the secondary sex characters of bourgeois males and (2) sperm had to be easily extruded from their vas deferens by gently pressing the abdomen (Gonçalves et al. 1996). The fish were fed once a day with common cockles Cerastoderma spp. In both the stock and the experimental tanks the photoperiod was adjusted according to natural conditions and the temperature kept at $22 \pm 2^{\circ} \mathrm{C}$. No mortality occurred during experiments. After testing all fish were released in the field at the same place where they were captured.

\section{Copying Experiments}

The general procedure followed Schlupp et al. (1994), Schlupp \& Ryan (1997) and Witte \& Ryan (1998). The experimental set-up consisted of a central tank $(80 \times 30 \mathrm{~cm})$ with two smaller tanks $(30 \times 15 \mathrm{~cm})$ adjacent to each top side (Fig. 1). These lateral tanks were used to restrain males and females presented to sneakers. The bottom of all tanks was covered by a 7-cm layer of sand and filled with sea water to $20 \mathrm{~cm}$. Illumination was provided by four $15-\mathrm{W}$ fluorescent lamps placed $55 \mathrm{~cm}$ above water level. Test fish were fed at least $2 \mathrm{~h}$ before experiments. We did the tests 2 days after catching the fish. 

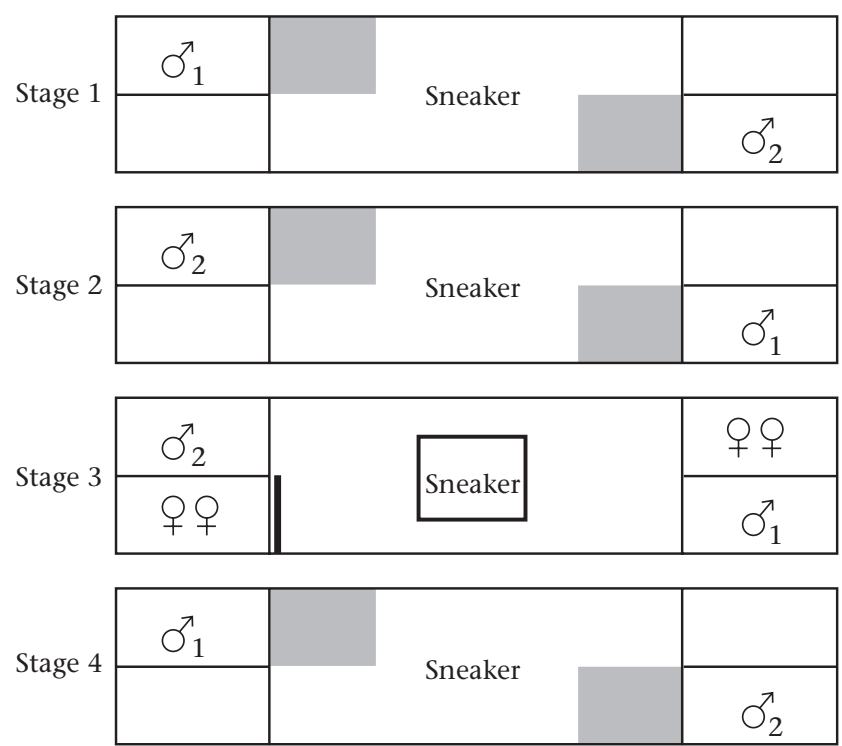

Figure 1. Top view of the experimental set-up. Stage 1: the sneaker could choose between males 1 and 2; stage 2: we switched the males between sides to test the consistency of the preference; stage 3: the nonpreferred male was presented in the company of females; stage 4: we switched the males between sides and again tested the sneaker's preference. The shaded areas were defined as preference zones.

The experimental procedure was divided into four stages.

(1) In stage 1 we tested the sneaker's preference for one of the males. Two bourgeois males were simultaneously introduced into two of the diagonally opposed smaller tanks to minimize interactions between them. These tanks contained an opaque glass box $(21 \times 5 \times 5.5 \mathrm{~cm})$ with an opening of $2.5 \times 2.5 \mathrm{~cm}$ turned to face the central tank to be used as a shelter by males. Males typically stayed with the head out of the shelter most of the time, which is also the most common position observed in the field (D. Gonçalves, personal observation). A sneaker was then introduced into a transparent glass container $(15 \times 15 \mathrm{~cm})$ and placed in the centre of the central tank for $10 \mathrm{~min}$. One half of a clay pot $(8 \mathrm{~cm}$ diameter $)$ turned to face the back wall of the central tank provided shelter for the sneaker. Sneakers usually spent most of their time inspecting the area and interacting with both males. After the 10 -min period we removed the glass container and recorded the sneaker's position with a video camera for another $10 \mathrm{~min}$. The time spent by the sneaker in an area of $20 \times 15 \mathrm{~cm}$ in front of each male tank (preference zone, Fig. 1) was quantified from videotapes using The Observer PC software version 3.0 (Noldus Information Technology, Wageningen, The Netherlands).

(2) In stage 2 we tested the consistency of the preference. We caught the sneaker with a hand net and switched the stimulus males between sides. The sneaker was then restrained in the glass container for another 10 min and the previous procedure was repeated (Fig. 1).

(3) In stage 3 we presented the nonpreferred male with females. If the tested sneaker showed a consistent preference for the same male (i.e. spent more than $66 \%$ of the total time spent in the preference areas with that male in stages 1 and 2 combined, Schlupp et al. 1994) we staged an encounter of the initially nonpreferred male with two females. To do this, we introduced two females matched for body size into each of the small tanks adjacent to the males' tanks (Fig. 1). This ensured that both males could interact with the females and that any effect was not due to differential stimulation of the males. Two females were used to guarantee that at least one would court the male. The females usually courted the males intensely and adopted the typical nuptial coloration. During the presentation, the sneaker was confined to the glass container. An opaque partition prevented the sneaker seeing the females in the tank adjacent to the previously preferred male (Fig. 1). The presentation lasted $10 \mathrm{~min}$.

(4) In stage 4 we retested the sneaker's preference. Another opaque partition was placed in front of the other female tank, we removed all females with a hand net and switched males between sides. The opaque partitions and the glass container were then removed and the sneaker's position recorded for another $10 \mathrm{~min}$ (Fig. 1).

As a control we repeated this experiment, but in stage 3 we prevented the sneaker seeing the females close to the nonpreferred male, so that both males had the opportunity to interact with the females but this interaction was hidden from the sneaker. No control for schooling was performed, because individuals do not school in this species (D. Gonçalves \& T. Fagundes, personal observations based on more than $100 \mathrm{~h}$ of field observations).

We defined a priori that if the sneaker or either of the bourgeois males spent more than $50 \%$ of the time completely inside the shelter in any of the experimental stages the trial would be aborted. This occurred in only four of 30 trials. We also considered that if a sneaker spent more than $80 \%$ of the time in one of the tank sides it showed a side bias (after Schlupp et al. 1994). However, this never happened.

We tested 26 sneakers (standard length: $\bar{X} \pm \mathrm{SE}=$ $5.42 \pm 0.10 \mathrm{~cm}$, range $4.5-6.6 \mathrm{~cm})$ in the experimental group and 13 in the control group $(5.39 \pm 0.18 \mathrm{~cm}$, range $4.6-6.5 \mathrm{~cm})$. Each sneaker was tested with a different pair of bourgeois males and we used a total of 39 males (standard length: $10.59 \pm 0.31 \mathrm{~cm}$, range $8.2-13.9 \mathrm{~cm}$ ). On the same day each bourgeois male was presented to two different sneakers, and paired with a different male each time. We allowed a variation of $13 \%$ in the paired males' body size (average 5.9\%, range 0-12.6\%).

Because the consistency test (stages 1 and 2) was common to the experimental and control groups, we combined the results from all fish to test whether sneakers prefer to associate with the larger of the two males. To test whether sneakers incorporate information from the choices of females to choose their hosts, we compared the time spent close to the nonpreferred male in stage 2 (just before the presentation of females) with the time spent close to that male after the presentation (stage 4).

The data were analysed with nonparametric statistics because they did not conform to parametric assumptions. All tests were two tailed. 


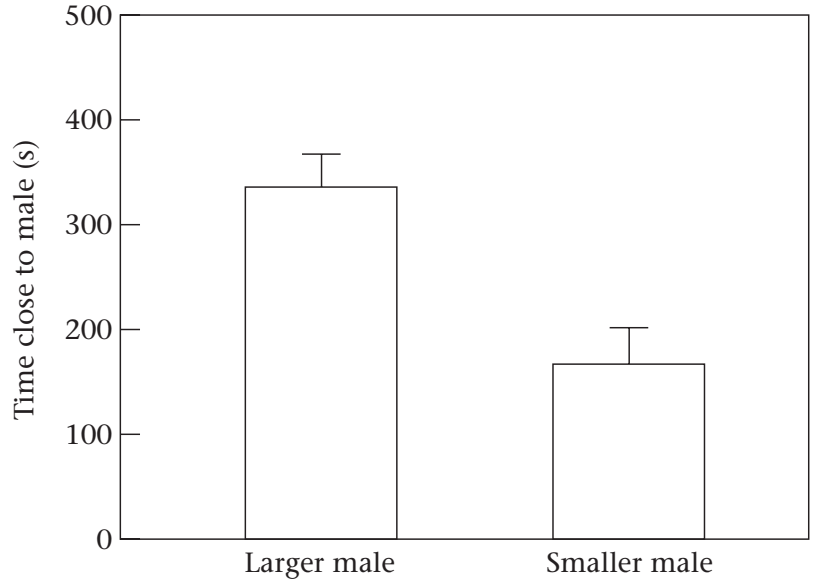

Figure 2. Time spent by sneakers near the larger and the smaller of the two males during stages 1 and $2(N=25)$. Results are expressed as $\bar{X}+1 \mathrm{SE}$.

\section{RESULTS}

\section{Independent Preference of Sneakers}

Of the 39 sneakers tested 25 showed a consistent preference for the same bourgeois male during stages 1 and 2 . Sneakers associated with the larger male in 15 trials and the smaller male in three $\left(\chi_{1}^{2}=8.0, P=0.005\right)$; in seven trials males were exactly the same size. Sneakers also spent more time close to the larger male (Wilcoxon test: $Z=2.5, N=18, P=0.011$; Fig. 2). The strength of the association did not correlate with the difference in size between males (Spearman rank correlation between the males' difference in body length and the difference in time spent close to both males: $r_{\mathrm{S}}=0.11, N=25, P=0.581$ ).

\section{Female Copying by Sneakers}

Of the 25 sneakers that consistently preferred the same bourgeois male, 16 were tested in the experimental group and nine in the control group. In the experimental group, after observing the nonpreferred male in the company of females, sneakers increased the time spent near that male $(Z=3.0, N=16, P=0.002$; Fig. 3a). In the control group, where no females were presented, there was no difference in time spent close to the nonpreferred male from the first to the second part of the experiment ( $T=20.0, N=9$, $P=0.767$; Fig. $3 b)$. The increase in time spent close to the previously nonpreferred male was significantly higher in the experimental group (Mann-Whitney test: $U=37.0$, $N_{\text {experimental }}=16, N_{\text {control }}=9, P=0.047$; Fig. 4 ).

Because of the preference for larger males, copying might occur only when the difference in body size between males is small or absent. However, the difference in time spent close to the nonpreferred male in the experimental group before and after treatment did not correlate significantly with the difference in the males' body length $\left(r_{\mathrm{S}}=0.2, N=16, P=0.396\right)$. The latency to enter the preference area of the nonpreferred male decreased when that male was observed with females,

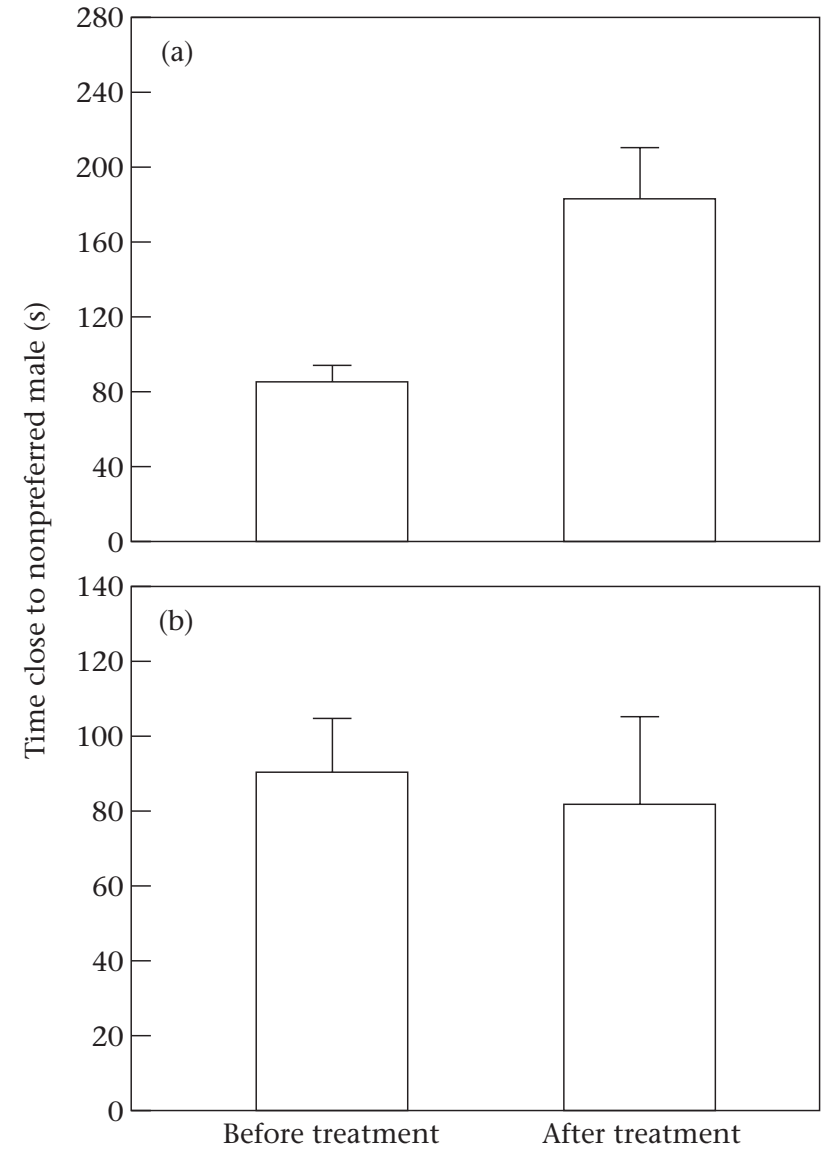

Figure 3. Time spent by sneakers near the nonpreferred male (a) in the experimental test $(N=16)$, before (stage 2$)$ and after (stage 4) observing that male in the company of females; (b) in the control test $(N=9)$, before (stage 2$)$ and after (stage 4$)$ observing that male alone. Results are expressed as $\bar{X}+1 \mathrm{SE}$.

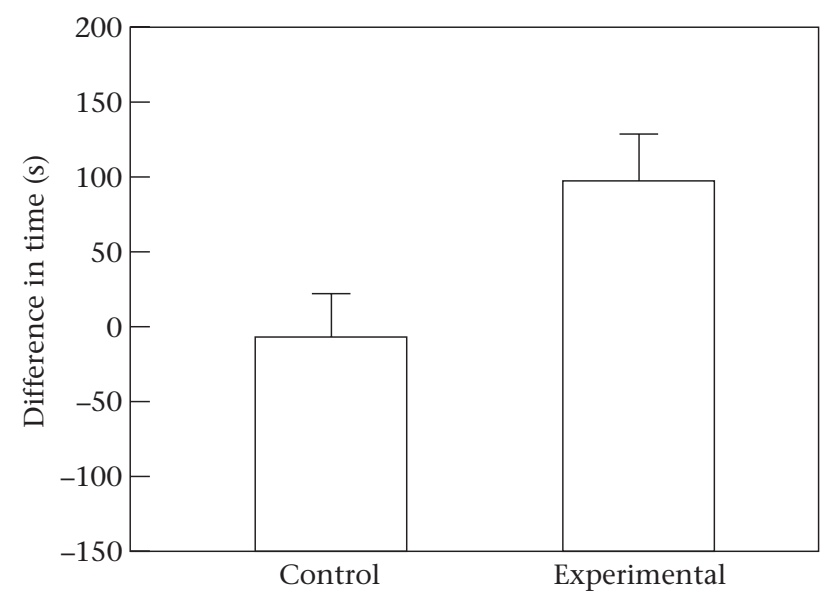

Figure 4. Difference in the time spent near the nonpreferred male (time after the test-time before the test), in the experimental $(N=16)$ and control $(N=9)$ groups. Results are expressed $\bar{X}+1 \mathrm{SE}$.

although this difference was not significant $(Z=1.7$, $N=16, P=0.084)$, but no differences were recorded in the control group ( $T=21.0, N=9, P=0.859)$. 


\section{DISCUSSION}

Our results indicate that $S$. pavo sneakers use two mechanisms to find opportunities to parasitize bourgeois males: they can choose potential host males independently, or they can incorporate social cues into their choices and copy the choices of mate-searching females.

Sneakers associated with the larger nesting male in the first part of the simultaneous choice tests. In field studies on the same population, larger males had more eggs inside their nests (Oliveira et al. 1999; Gonçalves et al. 2002), more sneakers were associated with their nests, and females preferred to spawn with them (T. Fagundes, D. Gonçalves \& R. Oliveira, unpublished data). Thus, female preferences appear to provide reliable information that can be imitated. The sneakers' association with larger males should increase their chances of achieving parasitic fertilizations, because those males will receive more eggs. Both females and sneakers thus seem to be able to choose males independently by body size. Associating with larger males is unlikely to decrease the sneakers' probability of achieving parasitic fertilizations of the eggs, because males are unable to discriminate females from sneakers and larger bourgeois males do not attack sneakers more often than smaller males (D. Gonçalves, T. Fagundes \& R. Oliveira, unpublished data).

Our results also show that nonindependent mechanisms influence the choices of sneakers. Sneakers spent more time close to a previously nonpreferred male when that male was previously observed in the company of females. Because we switched the males' positions in the choice tank after presenting the nonpreferred male in the company of females to sneakers, the latter were not simply associating with a place where females were or had just been seen. The sneakers were able to discriminate between the two males, retain information from a previous social encounter between a bourgeois male and females, and use that information in their future choice of hosts. To our knowledge this is the first demonstration of what we call 'intersexual copying'. Copying has primarily been investigated in the context of females copying other females, and has been defined as a situation where a female bases her mate choice on the direct observation of other females' choices (Dugatkin 1992; Kraak 1996). More generally, copying can be understood as a nonindependent mechanism in which an individual's choice of a specific resource is influenced by the direct observation of the choices of others. For sneakers of $S$. pavo both females and bourgeois males can be viewed as reproductive resources: females have to lay eggs for sneakers to parasitize them but the eggs do not survive without the bourgeois male's parental care. Thus, the fact that the sneakers' decision to associate with a particular bourgeois male is influenced by the choices of females can be interpreted in a copying context.

The visit of a female to a bourgeois male probably correlates with future visits by the same or by other females to that male, because females prefer to spawn with males that have both more eggs and a higher proportion of recently laid eggs (T. Fagundes, D. Gonçalves \& R. Oliveira, unpublished data). If this is the case, sneakers should benefit by associating with males previously seen being visited by females to increase the probability of witnessing future spawning events. Furthermore, females may be choosing males with high paternal care ability, as shown for other fish species (e.g. Pomatoschistus minutus: Forsgren 1997). Copying the choices of females could thus increase the probability of survival of the eggs parasitized by the sneakers. The association of parasitic males with nests that receive many visits from females has already been shown for sneakers of Symphodus tinca and Symphodus ocellatus by van den Berghe et al. (1989) and for satellite males of Parablennius sanguinolentus parvicornis by Oliveira et al. (2002). However, in these studies it was not possible to distinguish whether sneakers and satellites were being attracted to nests by the presence of females or by specific features of the successful bourgeois males or nests.

The use of information from female visits to males by sneakers can be viewed as a communication network (McGregor \& Peake 2000), in which a third party, the sneaker male, intercepts information not intended for it. Understanding how this is incorporated into the process of decision making is important. The nonindependent choice of sneakers is likely to lead to intersexual conflicts between bourgeois males, sneakers and females and influence both the female's and the male's mating decisions. From a bourgeois male's perspective, a courting female may ultimately represent fitness benefits but may also constitute a risk, as courting probably increases the probability of sneaking events, during both the present and future spawning episodes. For example, in the Mediterranean wrasse, S. ocellatus, males occasionally refuse courting females when sneakers surround the nest, reducing their immediate mating success. However, this behaviour leads to a reduction in the number of sneakers surrounding the nest and a subsequent increase in the male's mating rate (Alonzo \& Warner 1998). For S. pavo, field observations have shown that nesting males often reject courting females, which could also relate to an attempt to reduce future sneaking episodes (D. Gonçalves, T. Fagundes \& R. F. Oliveira, unpublished data). Alternatively, as bourgeois males of S. pavo are unable to discriminate females from small femalemimicking sneakers (D. Gonçalves, T. Fagundes, R. Matos \& R. F. Oliveira, unpublished data), courting females could be attacked because they are mistaken for sneakers. It would be interesting to test whether the levels of female rejection by the bourgeois male relates to the number and size of sneakers near the nest, and whether the male's rejection of females reduces the number of sneakers around the nest and influences the bourgeois male's future reproductive success (as demonstrated for S. ocellatus, Alonzo \& Warner 1998, 1999).

Nonindependent choice by sneakers may also lead to female intrasexual conflicts. In species with alternative male reproductive tactics, females prefer to mate with bourgeois males rather than with parasitic males (Taborsky 1994, 1999), and accordingly females of S. pavo are rarely seen to court sneakers in nature (D. Gonçalves, personal observations). Females may copy the choices of other females to decrease their sampling costs and avoid 
errors. However, if females copy the choices of other females they are likely to increase the probability of having some of their eggs fertilized by sneakers, as sneakers also copy the choices of females. To solve this conflict females may use the information from encounters between bourgeois males and females in their mating decisions, but at the same time choose spawning situations where sneakers are momentarily absent or in small numbers (as suggested for S. ocellatus: Wernerus et al. 1989; Alonzo \& Warner 1999). Clearly, future experimental work is necessary to understand fully the dynamic interactions that occur between and within the sexes in S. pavo.

We suggest that female copying by parasitic males is probably a widespread phenomenon among species with alternative reproductive tactics, but future experiments in other species are needed to support this hypothesis.

\section{Acknowledgments}

We are grateful to the Ria Formosa Nature Park, in particular its director Luís Fonseca, for providing essential logistical support. During this study D.M.G. was supported by a PRAXIS XXI Ph.D. grant (BD/13436/97). This study was funded by a Portuguese-German cooperation fund (DAAD/ICCTI).

\section{References}

Agrawal, A. F. 2001. The evolutionary consequences of mate copying on male traits. Behavioral Ecology and Sociobiology, 51, 33-40.

Almada, V. C., Gonçalves, E. J., Santos, A. J. \& Baptista, C. 1994. Breeding ecology and nest aggregations in a population of Salaria pavo (Pisces: Blenniidae) in an area where nest sites are very scarce. Journal of Fish Biology, 45, 819-830.

Almada, V. C., Gonçalves, E. J., Oliveira, R. F. \& Santos, A. J. 1995. Courting females: ecological constraints affect sex roles in a natural population of the blenniid fish, Salaria pavo. Animal Behaviour, 49, 1125-1127.

Alonzo, S. H. \& Warner, R. R. 1998. A trade-off generated by sexual conflict: Mediterranean wrasse males refuse present mates to increase future success. Behavioral Ecology, 10, 105-111.

Alonzo, S. H. \& Warner, R. R. 1999. Dynamic games and field experiments examining intra- and intersexual conflict: explaining counterintuitive mating behavior in a Mediterranean wrasse, Symphodus ocellatus. Behavioral Ecology, 11, 56-70.

van den Berghe, E. P., Wernerus, F. \& Warner, R. R. 1989. Female choice and the mating cost of satellite males: evidence of choice for good genes? Animal Behaviour, 38, 875-884.

Brooks, R. 1999. Mate choice copying in guppies: females avoid the place where they saw courtship. Behaviour, 136, 411-421.

Dugatkin, L. A. 1992. Sexual selection and imitation: females copy the mate choice of others. American Naturalist, 139, 1384-1389.

Dugatkin, L. A. 1998. A comment on Lafleur et al.'s re-evaluation of mate-choice copying in guppies. Animal Behaviour, 56, 513-514.

Dugatkin, L. A. \& Godin, J.-G. J. 1993. Female mate-copying in the guppy (Poecilia reticulata): age-dependent effects. Behavioral Ecology, 4, 289-292.

Fishelson, L. 1963. Observations on littoral fishes of Israel. I. Behaviour of Blennius pavo Risso (Teleostei: Blenniidae). Israel Journal of Zoology, 12, 67-80.
Fiske, P., Kålås, J. A. \& Sæther, S. A. 1996. Do female great snipe copy each other's mate choice? Animal Behaviour, 51, 13551362.

Forsgren, E. 1997. Female sand gobies prefer good fathers over dominant males. Proceedings of the Royal Society of London, Series B, 264, 1283-1286.

Galef, B. G. Jr \& White, D. J. 1998. Mate-choice copying in Japanese quail, Coturnix coturnix japonica. Animal Behaviour, 55, $545-552$.

Gonçalves, D., Simões, P. C., Chumbinho, A. C., Correia, M. J., Fagundes, T. \& Oliveira, R. F. 2002. Fluctuating asymmetries and reproductive success in the peacock blenny, Salaria pavo (Risso). Journal of Fish Biology, 60, 810-820.

Gonçalves, E. J., Almada, V. C., Oliveira, R. F. \& Santos, A. J. 1996. Female mimicry as a mating tactic in males of the blenniid fish Salaria pavo. Journal of the Marine Biological Association of the U.K., 76, 529-538.

Grant, J. W. A. \& Green, L. D. 1996. Mate-copying versus preference for actively courting males by female Japanese medaka (Oryzias latipes). Behavioral Ecology, 7, 165-167.

Höglund, J., Alatalo, R. V., Gibson, R. M. \& Lundberg, A. 1995. Mate choice copying in black grouse. Animal Behaviour, 49, 1627-1633.

Howard, R. D., Martens, R. S., Innis, S. A., Drnevich, J. M. \& Hale, J. 1998. Mate choice and mate competition influence male body size in Japanese medaka. Animal Behaviour, 55, 1151-1163.

Kraak, S. B. M. 1996. 'Copying mate choice': which phenomena deserve this term? Behavioural Processes, 36, 99-102.

Lafleur, D. L., Lozano, G. A. \& Sclafani, M. 1997. Female matecopying in guppies, Poecilia reticulata: a re-evaluation. Animal Behaviour, 54, 579-586.

Losey, G. S. Jr, Stanton, F. G., Telecky, T. M., Tyler, W. A. III \& The Zoology 691 Graduate Seminar Class 1986. Copying others, an evolutionary stable strategy for mate choice: a model. American Naturalist, 128, 653-664.

McGregor, P. K. \& Peake, T. M. 2000. Communication networks: social environments for receiving and signaling behaviour. Acta Ethologica, 2, 71-81.

Oliveira, R. F., Almada, V. C., Forsgren, E. \& Gonçalves, E. J. 1999. Temporal variation in male traits, nest aggregations and mating success in the peacock blenny, Salaria pavo. Journal of Fish Biology, 54, 499-512.

Oliveira, R. F., Carvalho, N., Miranda, J., Gonçalves, E. J., Grober, M. \& Santos, R. S. 2002. The relationship between the presence of satellite males and nest holders' mating success in the Azorean rock-pool blenny, Parablennius sanguinolentus parvicornis. Ethology, 108, 223-235.

Papaconstantinou, C. A. 1979. Secondary sex characters of Blennioid fishes (Pisces: Blenniidae). Thalassographica, 1, 57-75.

Patzner, R. A. \& Seiwald, M. 1987. The reproduction of Blennius pavo. II. Secondary sexual organs and accessory glands of the testis during the reproductive cycle. In: Proceedings of the $V$ Congress of European Ichthyologists (Ed. by S. Kullander \& B. Fernholm), pp. 293-298. Stockholm: Swedish Museum of Natural History.

Patzner, R. A., Seiwald, M., Adlgasser, M. \& Kaurin, G. 1986. The reproduction of Blennius pavo. $\mathrm{V}$. Reproductive behaviour in natural environment. Zoologisches Anzeiger, 216, 338-350.

Pruett-Jones, S. 1992. Independent versus non-independent matechoice: do females copy each other? American Naturalist, 140, 1000-1009.

Schlupp, I. \& Ryan, M. J. 1997. Male sailfin mollies (Poecilia latipinna) copy the mate choice of other males. Behavioral Ecology, 8, 104-107.

Schlupp, I., Marler, C. \& Ryan, M. J. 1994. Benefit to male sailfin mollies of mating with heterospecific females. Science, 263, 373374. 
Servedio, M. R. \& Kirkpatrick, M. 1996. The evolution of mate choice copying by indirect selection. American Naturalist, 148, 848-867.

Slagsvold, T. \& Viljugrein, H. 1999. Mate choice versus preference for actively displaying males by female pied flycatchers. Animal Behaviour, 57, 679-686.

Taborsky, M. 1994. Sneakers, satellites, and helpers: parasitic and cooperative behavior in fish reproduction. Advances in the Study of Behavior, 23, 1-100.

Taborsky, M. 1997. Bourgeois and parasitic tactics: do we need collective, functional terms for alternative reproductive behaviors? Behavioral Ecology and Sociobiology, 41, 361-362.

Taborsky, M. 1999. Conflict or cooperation? What determines optimal solutions to competition in fish reproduction? In: Behaviour and Conservation of Littoral Fishes (Ed. by V. C. Almada, R. F. Oliveira \& E. J. Gonçalves), pp. 301-349. Lisboa: ISPA.
Wernerus, F. M., Lejeune, P. \& van den Berghe, E. P. 1989. Transmission of mating success among neighbouring males in the Mediterranean labrid fish, Symphodus ocellatus. Biology of Behaviour, 14, 195-206.

Westneat, D. F., Walters, A., McCarthy, T. M., Hatch, M. I. \& Hein, W. K. 2000. Alternative mechanisms of non-independent mate-choice. Animal Behaviour, 59, 467-476.

Witte, K. \& Ryan, M. J. 1998. Male body length influences matechoice copying in the sailfin molly Poecilia latipinna. Behavioral Ecology, 9, 534-539.

Witte, K., Ryan, M. J. 2002. Mate choice copying in the sailfin molly, Poecilia latipinna, in the wild. Animal Behaviour, 63, 943949.

Zander, C. D. 1986. Blenniidae. In: Fishes on the North-Eastern Atlantic and the Mediterranean (Ed. by P. J. Whithead, M. L. Bauchot, J. C. Hureau, J. Nielsen \& E. Tortenese), pp. 1096-1112. Paris: UNESCO. 